\title{
JNPH
}

Volume 5 No. 1 (Juli 2017)

(C) The Author(s) 2017

\section{FAKTOR-FAKTOR YANG BERHUBUNGAN DENGAN KEJADIAN ULKUS DIABETIK PADA PENDERITA DIABETES MELITUS DI RS BHAYANGKARA TK III POLDA BENGKULU TAHUN 2016}

\section{FACTORS ASSOCIATED WITH DIABETIC ULCERS CASES ON PATIENTS WITH DIABETES MELLITUS IN BHAYANGKARA LEVEL III HOSPITAL IN BENGKULU 2016}

\author{
IDA SAMIDAH, MIRAWATI, DESI MARIYATI \\ SEKOLAH TINGGI ILMU KESEHATAN DEHASEN BENGKULU \\ Email : idasamidah@yahoo.com
}

\begin{abstract}
ABSTRAK
Di Indonesia kejadian diabetes mellitus termasuk urutan ke 7 terbesar di dunia yaitu 7,6 juta orang, sedangkan kejadian penderita ulkus diabetes sebesar 15\% penderita DM. Bahkan mortalitas dan amputasi masih tinggi yaitu 32,5\% dan 23,5\%. Tujuan dari penelitian ini adalah untuk mengetahui faktor-faktor yang berhubungan dengan kejadian ulkus diabetes pada pasien diabetes melitus di RS Bhayangkara Tingkat III Bengkulu 2016. Metodologi: Penelitian ini menggunakan desain cross sectional. Dengan populasi semua penderita diabetes melitus sebesar 964, sampel dari 91 responden diambil dengan teknik "Accidental Sampling". Hasil penelitian ini menunjukkan mayoritas responden $(63,7 \%)$ pasien DM memiliki rentang risiko hidup, mayoritas responden $(56,0 \%)$ menderita diabetes $\geq 10$ tahun, mayoritas responden $(39,6 \%)$ kurang melakukan perawatan kaki. Sebagian besar responden $(56,0 \%)$ mengalami borok, ada hubungan yang signifikan antara usia berisiko, lamanya menderita diabetes dan perawatan kaki dengan kejadian ulkus diabetes. Diharapkan dapat memperbaiki praktik konseling di bidang pengobatan diabetes melitus dengan ulkus diabetes.
\end{abstract}

Kata Kunci: umur, lama menderita DM, perawatan kaki, kejadian Diabetes Ulkus

\begin{abstract}
In Indonesia the incidence of diabetes mellitus including the 7th largest order of the world in the amount of 7.6 million people, while the incidence of patients with diabetic ulcers by $15 \%$ of patients with DM. Even mortality and amputation are still high at $32.5 \%$ and $23.5 \%$. The objective of this study was to determine the factors associated with the incidence of diabetic ulcers on patients with diabetes mellitus in Bhayangkara Level III hospital Bengkulu 2016. Methodology: This study used cross sectional design. With the population of all patients with diabetes mellitus by 964 , the samples of 91 respondents, taken by the technique of "Accidental Sampling". The results of this study showed the majority of respondents $(63.7 \%)$ patients with DM had a risk lifespan, the majority of respondents $(56.0 \%)$ were $\geq 10$ years of suffering from diabetes, the majority of respondents $(39.6 \%)$ conducted less foot care, most respondents $(56.0 \%)$ got ulcers, there was a significant association between age at-risk, length of suffering from diabetes and foot care with the incidence of diabetic ulcers. Expected to improve counseling practices in the field of treatment of diabetes mellitus with diabetic ulcers.
\end{abstract}


Keywords: age, length of suffering from diabetes, foot care and incidence of ulcers

\section{PENDAHULUAN}

Kenaikan jumlah penderita DM memiliki pengaruh besar pada peningkatan komplikasi pada pasien diabetes. Salah satu komplikasi yang menimbulkan permasalahan yang besar pada penderita diabetes adalah munculnya permasalahan pada kaki. Permasalahan yang timbul di kaki dapat mengakibatkan amputasi hingga kematian jika tidak dilakukan pencegahan sejak penderita terdiagnosa diabetes mellitus (Prastica, 2013).

\section{METODE PENELITIAN}

Teknik pengumpulan data yang digunakan dalam penelitian ini adalah dengan menggunakan data primer dan data sekunder. Data primer dikumpulkan dengan cara wawancara dan menyebarkan kuesioner kepada responden untuk mendapatkan data tentang status gizi, perilaku mencuci tangan dan penyediaan air bersih. Data sekunder dalam penelitian ini adalah data dari catatan pengarsipan diare di Rekam Medik RS Bhayangkara TK III Polda Bengkulu tentang diagnosa medis.

Munculnya luka pada kaki diabetik ditandai dengan adanya luka terbuka pada permukaan kulit sehingga mengakibatkan infeksi sebagai akibat dari masuknya kuman atau bakteri pada permukaan luka. Banyak faktor yang mempengaruhi timbulnya luka kaki diabetik yang meliputi, riwayat $\mathrm{DM} \geq 10$ tahun, laki-laki perokok aktif, kadar glukosa darah yang tidak terkontrol, gangguan penglihatan yang dapat berpengaruh pada kemampuan melakukan perawatan kaki, polineuropati, trauma kaki (lecet), kekurangan latihan fisik, pengetahuan tentang penyakit DM yang kurang, tidak maksimalnya kepatuhan dalam pencegahan luka, kadar kolesterol $\geq 200 \mathrm{mg} / \mathrm{dl}$, kadar HDL $\leq 45 \mathrm{mg} / \mathrm{dl}$, ketidakpatuhan diit rendah gula, perawatan kaki yang tidak teratur, penggunaan alas kaki yang tidak tepat, hal-hal tersebut dapat menjadi faktor pemicu timbunya luka sebesar $99,9 \%$ dari kasus yang ditimbulkan (Hartini, 2009).

Berdasarkan survei awal pada tanggal 01-03 Februari 2016 terdapat 8 pasien yang mengalami penyakit DM, 6 diantaranya terdapat ulkus diabetikum. 5 penderita yang berumur $\geq 60$ tahun, 3 penderita lainnya berumur $<60$ tahun. 4 penderita mengatakan bahwa sudah $\geq 10$ tahun menderita penyakit DM, 4 penderita lainnya $<10$ tahun menderita DM. Perawatan kaki DM dilakukan dengan baik sebanyak 1 pasien, 3 penderita melakukan perawatan kaki DM yang cukup baik dan 4 penderita lainnya melakukan perawatan kaki DM yang kurang baik.

Berdasarkan uraian latar belakang tersebut maka peneliti tertarik untuk meneliti tentang faktor-faktor yang berhubungan dengan kejadian ulkus diabetik di RS Bhayangkara TK III Polda Bengkulu Tahun 2016.

\section{HASIL PENELITIAN}

Rumah Sakit Bhayangkara Bengkulu ditetapkan menjadi rumah sakit umum kelas C melalui surat Keputusan Menteri Kesehatan Republik Indonesia No : HK.03.05/I/1346/12 tanggal 13 Juli 2012 tentang penetapan kelas Rumah Sakit Umum Bhayangkara Jitra Kota Bengkulu dan berdasarkan keputusan kapolri no : kep/546/IX/2012 tanggal 26 september 2012 tentang peningkatan Rumah Sakit Bhayangkara Kepolisian Negara Republik Indonesia, Rumah Sakit Bhayangkara Bengkulu ditingkatkan dari tingkat IV ke tingkat III.

Tabel 1 Distribusi frekuensi responden umur penderita DM di RS Bhayangkara TK III Polda Bengkulu Tahun 2016

\begin{tabular}{ccc}
\hline Umur & Frekuensi & Presentase (\%) \\
\hline Tidak beresiko & 33 & 36,3 \\
Ya Beresiko & 58 & 63,7 \\
\hline
\end{tabular}




\begin{tabular}{ccc}
\hline Jumlah & 91 & 100 \\
\hline
\end{tabular}

Tabel 1 menunjukkan bahwa lebih sebagian besar responden $(63,7 \%)$ penderita DM memiliki umur yang bersiko.

Tabel 2 Distribusi frekuensi responden lama menderita DM di RS Bhayangkara TK III Polda Bengkulu Tahun 2016

\begin{tabular}{ccc}
\hline Lama Menderita & Frekuensi & Presentase (\%) \\
\hline$<10$ tahun & 40 & 44,0 \\
$\geq 10$ tahun & 51 & 56,0 \\
\hline Jumlah & 91 & 100 \\
\hline
\end{tabular}

Tabel 2 menunjukkan bahwa lebih sebagian besar responden $(56,0 \%) \geq 10$ tahun menderita DM.

Tabel 3 Distribusi frekuensi responden perawatan kaki penderita DM di RS Bhayangkara TK III Polda Bengkulu Tahun 2016

\begin{tabular}{ccc}
\hline $\begin{array}{c}\text { Perawatan } \\
\text { Kaki }\end{array}$ & Frekuensi & Presentase (\%) \\
\hline Baik & 25 & 27,5 \\
Cukup & 30 & 33,0 \\
Kurang & 36 & 39,6 \\
\hline Jumlah & 91 & 100 \\
\hline
\end{tabular}

Tabel 3 menunjukkan bahwa hampir sebagian besar responden $(39,6 \%)$ yang melakukan perawatan kaki yang kurang.

Tabel 4 Distribusi frekuensi responden kejadian Ulkus Diabetikum pada Penderita DM di RS Bhayangkara TK III Polda Bengkulu Tahun 2016

\begin{tabular}{ccc}
\hline Variabel & Frekuensi & Presentase (\%) \\
\hline $\begin{array}{c}\text { Tidak terjadi } \\
\text { ulkus }\end{array}$ & 40 & 44,0 \\
Terjadi ulkus & 51 & 56,0 \\
\hline Jumlah & 91 & 100 \\
\hline
\end{tabular}

Tabel 4 menunjukkan bahwa lebih sebagian besar responden $(56,0 \%)$ yang.terjadi ulkus.
Tabel 5 Hubungan umur penderita DM dengan kejadian Ulkus Diabetikum di RS Bhayangkara TK III Polda Bengkulu Tahun 2016

\begin{tabular}{|c|c|c|c|c|c|c|c|c|}
\hline \multirow[t]{2}{*}{ Umur } & \multicolumn{4}{|c|}{ Kejadian Ulkus } & \multirow[b]{2}{*}{$\begin{array}{l}\text { Juml } \\
\text { ah }\end{array}$} & \multirow[b]{2}{*}{$\%$} & \multirow[b]{2}{*}{$X^{2}$} & \multirow[b]{2}{*}{$p$} \\
\hline & $\begin{array}{l}\text { Tidak } \\
\text { Terja- } \\
\text { di } \\
\text { Ulkus }\end{array}$ & $\%$ & $\begin{array}{l}\text { Terja } \\
\text {-di } \\
\text { Ulk- } \\
\text { us }\end{array}$ & $\%$ & & & & \\
\hline $\begin{array}{l}\text { Tidak } \\
\text { Beri- } \\
\text { siko }\end{array}$ & 21 & $\begin{array}{l}63 \\
6\end{array}$ & 12 & $\begin{array}{l}36 \\
4\end{array}$ & 33 & $\begin{array}{l}10 \\
0\end{array}$ & & \\
\hline $\begin{array}{l}\text { Ya } \\
\text { Beris- } \\
\text { iko }\end{array}$ & 19 & $\begin{array}{l}25 \\
5\end{array}$ & 39 & $\begin{array}{l}32, \\
5\end{array}$ & 58 & $\begin{array}{l}10 \\
0\end{array}$ & $\begin{array}{l}6,93 \\
5\end{array}$ & $\begin{array}{l}0,00 \\
8\end{array}$ \\
\hline Total & 40 & $\begin{array}{l}44, \\
0\end{array}$ & 51 & $\begin{array}{l}56, \\
0\end{array}$ & 91 & $\begin{array}{l}10 \\
0\end{array}$ & & \\
\hline
\end{tabular}

Hasil analisis tabel 5 menunjukkan bahwa dari 58 responden dengan umur yang berisiko, hampir sebagian responden $(32,5 \%)$ terjadi ulkus. Dari analisis tersebut juga didapatkan chi-square $\left(\mathrm{X}^{2}\right)=6.935$ dan nilai $p=0,008$ yang lebih kecil dari alpha 5\% sehingga $\mathrm{Ha}$ diterima, berarti terdapat hubungan yang bermakna antara umur pasien DM dengan kejadian ulkus diabetik.

Tabel 6 Hubungan lama menderita DM dengan kejadian Ulkus Diabetikum di RS Bhayangkara TK III Polda Bengkulu Tahun 2016

\begin{tabular}{|c|c|c|c|c|c|c|c|c|}
\hline \multirow{2}{*}{$\begin{array}{l}\text { Lama } \\
\text { Men- } \\
\text { derita }\end{array}$} & \multicolumn{4}{|c|}{ Kejadian Ulkus } & \multirow[b]{2}{*}{$\begin{array}{l}\text { Jum- } \\
\text { lah }\end{array}$} & \multirow[b]{2}{*}{$\%$} & \multirow[b]{2}{*}{$X^{2}$} & \multirow[b]{2}{*}{$p$} \\
\hline & $\begin{array}{l}\text { Tidak } \\
\text { Terja- } \\
\text { di } \\
\text { Ulkus }\end{array}$ & $\%$ & $\begin{array}{l}\text { Terj } \\
\text { adi } \\
\text { Ulk- } \\
\text { us }\end{array}$ & $\%$ & & & & \\
\hline $\begin{array}{l}<10 \\
\text { tahun }\end{array}$ & 23 & $\begin{array}{l}57 \\
, 5\end{array}$ & 17 & 42,5 & 40 & 100 & & \\
\hline $\begin{array}{l}\geq 10 \\
\text { tahun }\end{array}$ & 17 & $\begin{array}{l}33 \\
3\end{array}$ & 34 & 66,7 & 51 & 100 & $\begin{array}{l}4,3 \\
70\end{array}$ & $\begin{array}{l}0,0 \\
36\end{array}$ \\
\hline Total & 40 & $\begin{array}{l}44 \\
, 0\end{array}$ & 51 & 56,0 & 91 & 100 & & \\
\hline
\end{tabular}

Hasil analisis tabel 6 menunjukkan bahwa dari 51 responden yang lama 
menderita $\mathrm{DM} \geq 10$ tahun, hampir sebagian responden $(32,5 \%)$ terjadi ulkus. Dari analisis tersebut juga didapatkan chi-square $\left(\mathrm{X}^{2}\right)=$ 4,379 dan nilai $p=0,036$ yang lebih kecil dari alpha 5\% sehingga $\mathrm{Ha}$ diterima, berarti terdapat hubungan yang bermakna antara lama menderita DM dengan kejadian ulkus diabetik.

Tabel 7 Hubungan perawatan kaki dengan kejadian Ulkus Diabetikum di RS Bhayangkara TK III Polda Bengkulu Tahun 2016

\begin{tabular}{|c|c|c|c|c|c|c|}
\hline \multirow{2}{*}{$\begin{array}{l}\text { Peraw- } \\
\text { atan } \\
\text { Kaki }\end{array}$} & \multicolumn{3}{|c|}{ Kejadian Ulkus } & \multirow[b]{2}{*}{$\begin{array}{l}\text { Jum } \\
\text { lah }\end{array}$} & \multirow[b]{2}{*}{$\% X^{2}$} & \multirow[b]{2}{*}{$p$} \\
\hline & $\begin{array}{l}\text { Tidak } \\
\text { Terja- } \\
\text { di } \\
\text { Ulkus }\end{array}$ & $\%$ & $\begin{array}{ll}\text { Terja- } & \% \\
\text { di } & \\
\text { Ulk- } & \\
\text { us } & \end{array}$ & & & \\
\hline
\end{tabular}

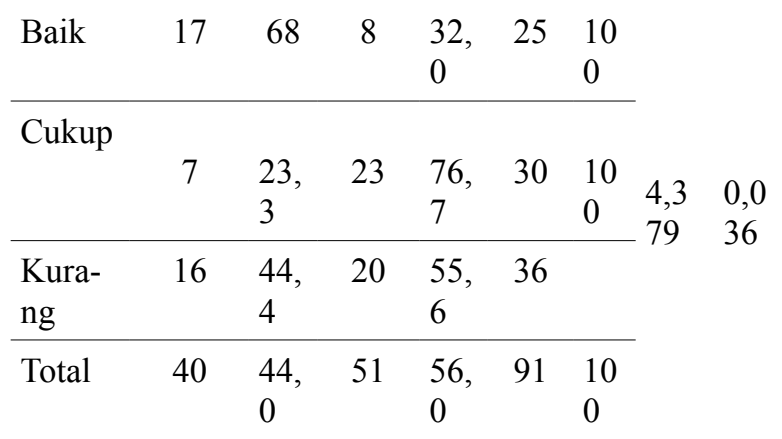

Hasil analisis tabel 7 menunjukkan bahwa dari 36 responden melakukan perawatan kaki yang kurang, sebagian besar responden $(55,6 \%)$ terjadi ulkus. Dari analisis tersebut juga didapatkan chi-square $\left(\mathrm{X}^{2}\right)=11,050$ dan nilai $p=0,004$ yang lebih kecil dari alpha 5\% sehingga Ha diterima, berarti terdapat hubungan yang bermakna antara perawatan kaki dengan kejadian ulkus diabetik.

\section{PEMBAHASAN}

Berdasarkan tabel 1 menunjukkan bahwa sebagian besar responden $(63,7 \%)$ penderita DM memiliki umur yang beresiko (61 Tahun). Usia diatas 60 tahun merupakan salah satu faktor resiko penyakit DM. Pada penderita DM yang mengalami ulkus diabetikum yang terbanyak adalah usia lanjut, hal ini karena usia lanjut mengalami perubahan-perubahan seperti berkurangnya massa otot dan perubahan vaskuler berkaitan dengan terjadinya resistensi insulin perifer pada DM. Berdasarkan tabel 2 menunjukkan bahwa sebagian besar responden $(56,0 \%) \geq$ 10 tahun menderita DM. Hasil ini menunjukkan bahwa Diabetes Mellitus merupakan sekelompok kelainan heterogen yang ditandai oleh kenaikan kadar glukosa dalam darah (lebih dari $100 \mathrm{mg} / \mathrm{l}$ ). Glukosa secara normal bersirkulasi dalam jumlah tertentu dalam darah. Glukosa dibentuk di hati dari makanan yang dikonsumsi (Brunner \& Suddarth, 2001). Berdasarkan tabel 2 menunjukkan bahwa sebagian besar responden $\quad(39,6 \%) \quad$ yang.melakukan perawatan kaki yang kurang, hal ini berarti pasien DM lebih banyak kurang melakukan perawatan kaki dibandingkan dengan melakukannya dengan baik. Berdasarkan tabel 2 bahwa sebagian besar responden $(56,0 \%)$ yang terjadi ulkus, hal ini dikarenakan pengetahuan pasien yang terkena DM yang kurang dan tidak melakukan perawatan kaki agar tidak terjadi ulkus serta tidak dapat melakukan perawatan ulkus diabetik secara benar, saat kadar gula darah turun mendekati normal maka tidak pernah lagi memeriksa kadar gula darah dan saat terjadinya luka, luka tidak sembuh bahkan keadaan luka bertambah parah. Hasil analisis tabel 5 menunjukkan bahwa dari 58 responden dengan umur yang berisiko, hampir sebagian responden $(32,5 \%)$ terjadi ulkus. Dari analisis tersebut juga didapatkan chi-square $\left(\mathrm{X}^{2}\right)=6.935$ dan nilai $p=0,008$ yang lebih kecil dari alpha 5\% sehingga $\mathrm{Ha}$ diterima, berarti terdapat hubungan yang bermakna antara umur yang bersiko dengan kejadian ulkus diabetik. Hasil analisis tabel 6 menunjukkan bahwa dari 51 responden yang lama menderita $\mathrm{DM} \geq 10$ tahun, hampir sebagian responden $(32,5 \%)$ terjadi ulkus. Dari analisis tersebut juga didapatkan chi-square $\left(\mathrm{X}^{2}\right)=4,379$ dan nilai $p=0,036$ yang lebih kecil dari alpha 5\% sehingga $\mathrm{Ha}$ diterima, berarti terdapat hubungan yang bermakna antara lama 
menderita DM dengan kejadian ulkus diabetik. Hasil penelitian menunjukkan bahwa lama menderita lebih dari 10 tahun semakin mengalami ulkus, karena kadar glukosa darah tidak terkendali, akan muncul komplikasi yang berhubungan dengan vaskuler. Hasil analisis tabel 6 menunjukkan bahwa dari 51 responden yang lama menderita $\mathrm{DM} \geq 10$ tahun, hampir sebagian responden $(32,5 \%)$ terjadi ulkus. Dari analisis tersebut juga didapatkan chisquare $\left(\mathrm{X}^{2}\right)=11,050$ dan nilai $p=0,004$ yang lebih kecil dari alpha 5\% sehingga $\mathrm{Ha}$ diterima, berarti terdapat hubungan yang bermakna antara perawatan kaki dengan kejadian ulkus diabetik.

\section{KESIMPULAN}

1. Lebih sebagian besar responden umur penderita DM berisiko untuk terjadi Ulkus diabetikum

2. Lebih sebagian besar responden lama menderita DM pada pasien $\mathrm{DM} \geq 10$ tahun

3. Hampir sebagian besar responden kurang dalam melakukan perawatan kaki DM pada pasien DM

4. Lebih sebagian besar responden mengalami ulkus diabetik pada penderita DM

5. Ada hubungan umur dengan kejadian ulkus diabetik pada penderita DM

6. Ada hubungan lama dengan kejadian ulkus diabetik pada penderita DM

7. Ada hubungan perawatan kaki DM dengan kejadian ulkus diabetik pada pasien DM

\section{SARAN}

\section{Praktis}

Petugas kesehatan diharapkan dapat meningkatkan komunikasi, informasi, dan edukasi tentang pentingnya perawatan kaki diabetes pada penderita DM agar tidak atau mengurangi resiko terjadinya ulkus diabetikum. Serta diharapkan dapat memotivasi dan meningkatkan kinerja dalam memberikan pelayanan asuhan keperawatan klien ulkus diabetik.

\section{Teoritis}

Bagi akademika diharapkan dapat memberikan informasi melalui penyuluhan tentang perawatan diabetes mellitus dengan kejadian ulkus diabetik. Bagi peneliti selanjutnya sebagai dasar untuk melakukan penelitian berikutnya yang berhubungan dengan perawatan kaki diabetes atau yang berhubungan dengan pencegahan ulkus diabetik lainnya.

\section{DAFTAR PUSTAKA}

Prastica, V.A. 2013. Perbedaan angka kejadian ulkus diabetikum pada pasien Diabetes Mellitus dengan dan tanpa hipertensi di RSUD Dr. Saiful

Anwar Malang. Diperoleh tanggal 16 Desember 2015 dari http://old.fk.ub.ac.id.

Rahmat, W.P. 2010. Pengaruh konseling terhadap kecemasan dan kualitas hidup pasien Diabetes Mellitus di Kecamatan Kebakkramat. Tesis. Diperoleh tanggal 16 Desember 2015 dari eprints.uns.ac.id. 